\title{
Correction to: Aminoglycoside Damage and Hair Cell Regeneration in the Chicken Utricle
}

\author{
Mirko Scheibinger, ${ }^{1}$ Daniel C. Ellwanger, ${ }^{1}$ C. Eduardo Corrales, ${ }^{1,2}$ Jennifer S. Stone, ${ }^{3}$ \\ and STEFan Heller ${ }^{1}$ \\ ${ }^{1}$ Department of Otolaryngology—Head and Neck Surgery, Stanford University School of Medicine, Stanford, CA 94305, USA \\ ${ }^{2}$ Department of Otology and Laryngology, Harvard Medical School and Brigham and Woman's Hospital, Boston, MA 02115, \\ USA \\ ${ }^{3}$ Department of Otolaryngology—Head and Neck Surgery, Virginia Merrill Bloedel Hearing Research Center, University of Washington, \\ Seattle, WA 98195, USA
}

\author{
Correction to: JARO \\ https://doi.org/10.1007/s10162- \\ 017-0646-4
}

This article was updated to correct a formatting error in Table 1.

Present address: C. Eduardo Corrales, Department of Otology and Laryngology, Harvard Medical School and Brigham and Woman's Hospital, Boston, MA 02115, USA.

The online version of the original article can be found at https:/ /

doi.org/10.1007/s10162-017-0646-4

Correspondence to: Mirko Scheibinger - Department of Otolaryngology—Head and Neck Surgery · Stanford University School of Medicine - Stanford, CA 94305, USA. Telephone: 650-704-4112; email: mscheib@stanford.edu 